\title{
ANALISIS MODEL SISTEM ANTRIAN PADA PELAYANAN ADMINISTRASI
}

\author{
Maxsi Ary \\ Universitas Bina Sarana Informatika Kampus Kota Surakarta \\ maxsiary@gmail.com
}

\begin{abstract}
Abstrak - Tujuan dari penelitian ini adalah menganalisis model sistem antrian yang digunakan pada bagian pelayanan administrasi kampus AMIK BSI Bandung. Analisa model sistem antrian memiliki pola kedatangan berdistribusi poisson, dan ukuran keefektifan sistem antrian menggunakan WinQSB. Model antrian pada pelayanan administrasi kampus menggunakan single channel single phase. Hasil analisis model sistem antrian menunjukkan bahwa tidak perlu penambahan petugas pelayanan dengan idle time lebih besar dari 83\%. Model pola kedatangan berdistribusi poisson, ukuran keefektifan pelayanan administrasi 8,33\% untuk rata-rata kedatangan 1, 16.67\% untuk rata-rata kedatangan 2, dan 25\% untuk rata-rata kedatangan 3, sedangkan asumsi rata-rata pelayanan adalah 12 .
\end{abstract}

Kata kunci : Sistem Antrian, Model Sistem Antrian, Ukuran Keefektifan, WinQSB.

\begin{abstract}
The purpose of this research is to analyze the model of queuing system used in the administration of campus AMIK BSI Bandung. The queue system model analysis has a Poisson distributed arrival pattern, and the queue system's queue effectiveness uses WinQSB. Model queue on campus administration services using single channel single phase. The result of queuing system model analysis shows that there is no need for additional service officer with idle time greater than $83 \%$. The model of arrival pattern is Poisson distributed administrative service effectiveness measure $8.33 \%$ for average arrival 1, 16.67\% for arrival average 2, and 25\% for arrival average 3, while the average service assumption is 12 .
\end{abstract}

\section{Keywords : Queue System, Queue System Model, Measures of Effectiveness, WinQSB.}

\section{PENDAHULUAN}

Kehidupan sehari-hari pasti berjumpa dengan kata antri, mengantri, antrian, antrilah di loket, situasi menunggu, dan kata lainnya dengan maksud mendapatkan pelayanan (Widjaja \& Deswindi, 2010), (Rahayu, Wasono, \& Utami, 2017), (Septiani, Wigati, \& Fatmasari, 2017). Sehingga antrian ini menjadi menarik (trending topic) untuk diteliti (Widjaja \& Deswindi, 2010), (Rahayu, Wasono, \& Utami, 2017), (Nurfitria, Nureni, \& Utami, 2016).

Hampir semua sependapat bahwa apabila antrian yang terjadi cukup panjang, maka dapat menimbulkan persepsi tersendiri bagi kepuasan yang membutuhkan pelayanan (Septiani, Wigati, \& Fatmasari, 2017), (Widjaja \& Deswindi, 2010), (Kakiay, 2004), (Nurfitria, Nureni, \& Utami, 2016). Sehingga permasalahan antrian harus di selesaikan dengan cepat dan tepat dalam penyelenggaraan jasa pelayanan.

Teori antrian berhubungan dengan pelanggan harus antri untuk mendapatkan suatu pelayanan. Terdapat beberapa cara untuk meneliti antrian, yaitu pendekatan riset operasi dan simulasi (Widjaja \& Deswindi, 2010), (Nurhayati \& Kartono, 2014). Sedangkan menurut beberapa penelitian menyebutkan bahwa proses antrian adalah proses kedatangan kemudian menunggu dalam baris (antrian) jika pelayanan sibuk, dan akhirnya meninggalkan fasilitas setelah dilayani (Rahayu, Wasono, \& Utami, 2017), (Septiani, Wigati, \& Fatmasari, 2017), (Nurfitria, Nureni, \& Utami, 2016), (Siregar, 2015), (Faisal, 2005), (Nurhayati \& Kartono, 2014). Sedangkan untuk proses analisa antrian pelayanan, ditentukan terlebih dahulu model sistem antriannya.

Persoalan antrian merupakan hal yang mendasari dari antrian untuk bisa mendapatkan pelayanan. Persoalan antrian ini disebabkan oleh banyaknya yang datang atau pelanggan yang ingin dilayani sedangkan jumlah pelayan terbatas. Contoh permasalahan antrian bisa ditemukan pada antrian teller bank, antrian pengisian bahan bakar minyak, antrian kantor pos, antrian tiket kendaraan umum, antrian pasar swalayan, antrian administrasi sekolah atau perguruan tinggi, antrian pasien rumah sakit, dan lain sebagainya.

AMIK BSI Bandung merupakan salah satu perguruan tinggi swasta di Kota Bandung. Bukan menjadi permasalahan yang serius berkenaan dengan proses pelayanan pada bagian administrasi. Penelitian yang dilakukan untuk mengetahui sistem antrian pada pelayanan administrasi kampus AMIK BSI Bandung memiliki pola waktu pelayanan berdistribusi eksponensial, dan ukuran keefektifan sistem antrian menggunakan WinQSB.

Sistem antrian pada administrasi kampus AMIK BSI Bandung termasuk single channel single phase (satu saluran satu tahap) yang memiliki satu fasilitas pelayanan yang dialiri oleh suatu antrian tunggal. Penelitian ini dibuat mulai dari analisis sitem antrian yang sudah diterapkan dan pengambilan sampai pengolahan data menggunakan SPSS sampai penentuan jumlah administrasi ideal dengan memenuhi stady state $<1$ dengan distribusi dan parameter ukuran keefektifan pelayanan menggunakan WinQSB. 


\section{KAJIAN PUSTAKA DAN PERUMUSAN HIPOTESIS}

\section{Model Antrian}

Teori antrian (queuing theory) merupakan salah satu bagian dari teori probabilitas (probabilistic theory) (Taha, 1996). Implementasi dari teori antrian ini salah satunya digunakan untuk menguraikan kemacetan lalu lintas telepon. Penulisan model antrian mengikuti notasi Kendall dengan bentuk a/b/c, kemudian ditambahkan simbol ddan e sehingga menjadi bentuk $\mathrm{a} / \mathrm{b} / \mathrm{c} / \mathrm{d} / \mathrm{e}$. Simbol tersebut diberi nama notasi KendallLee (Taha, 1996).

Proses penentuan model antrian dalam sistem antrian harus memperhatikan unsur-unsur dasar pendukungnya. Unsur-unsur dasar tersebut dijadikan referensi atau acuan oleh penyedia fasilitas layanan dalam memberikan pelayanan terhadap para pelanggan. Salah satu unsur dasar pada sistem antrian adalah pola kedatangan pelanggan. Alur proses kedatangan pelanggan dapat terjadi secara individu maupun berkelompok, baik dalam jumlah kecil maupun dalam jumlah besar. Pola atau alur kedatangan dapat dilihat dari waktu antar kedatangan dua pelanggan yang berurutan (interarrival time). Pola kedatangan pelanggan yang terjadi dapat bersifat deterministic (pasti) maupun stokastik (acak).

Teori antrian merupakan teori yang menyangkut studi matematis dari antrian-antrian atau baris-baris penungguan (Taha, 1996). Formasi baris-baris penungguan merupakan sesuatu yang biasa terjadi apabila kebutuhan akan suatu pelayanan melebihi kapasitas yang tersedia untuk menyelenggarakan pelayanan tersebut. Tujuan utama teori antrian mencapai keseimbangan antara ongkos pelayanan dengan ongkos yang disebabkan oleh adanya waktu menunggu tersebut.

\section{Asumsi Model Antrian}

Perhatikan kondisi antrian (Subekti \& Binatari, 2017) dimana kedatangan terjadi selama interval waktu dikendalikan oleh beberapa asumsi berikut:

Asumsi 1 : peluang suatu kedatangan terjadi antara $t$ dan $t+s$ hanya bergantung pada panjang $s$, artinya peluang tidak bergantung pada $t$ atau banyaknya kejadian yang terjadi selama periode waktu $(0, t)$

Asumsi 2 : peluang suatu kejadian terjadi dalam interval waktu yang singkat $h$ adalah positif tetapi kurang dari satu

Asumsi 3 : setidaknya ada satu kejadian yang terjadi dalam interval waktu singkat $h$

Proses Poisson merupakan suatu proses banyaknya kejadian selama interval waktu tertentu adalah Poisson, dan interval waktu antara dua kejadian berturut-turut adalah exponensial (Gross \& Harris, 1998). Proses Poisson ini ditunjukkan menggunakan ketiga asumsi tersebut (Subekti \& Binatari, 2017).

Secara umum model antrian diasumsikan jika rata-rata kedatangan dan rata-rata pelayanan berdistribusi Poisson, maka waktu antar kedatangan dan waktu pelayanan berdistribusi Eksponensial (Gross \& Harris, 1998). Jadi penentuan model antrian Poisson memiliki dua asumsi yang harus diperhatikan terkait dengan distribusi data, yaitu data berdistribusi Poisson dan data berdistribusi Eksponensial (Gross \& Harris, 1998).

\section{METODE PENELITIAN}

Metode penelitian yang digunakan melalui beberapa tahapan, yaitu pengumpulan data pada bagian administrasi, analisa hasil model antrian, dan analisis hasil model antrian menggunakan WinQSB.

Metode pengumpulan data melalui observasi, yaitu pengamatan langsung pada sistem antrian pelayanan pada administrasi kampus AMIK BSI Bandung. Pengambilan data dilakukan selama dua hari (17-18 Januari 2018), waktu pengambilan data pada tanggal 17 Januari 2018 dilakukan pada pukul $14.15-21.15$ WIB (satu sift), sedangkan pada tanggal 18 Januari 2018 dilakukan pada pukul $07.30-21.15$ WIB (dua sift).

Pengumpulan data yang berkenaan dengan kedatangan dan pelayanan dengan metode observasi yaitu mengukur waktu antara kedatangan dan selesai pelayanan yang berturut-turut untuk memperoleh waktu lama pelayanan. Menghitung jumlah kedatangan selama satu satuan waktu yang dipilih adalah 30 menit.

Analisis data dilakukan dengan langkah-langkah sebagai berikut:

1. Menentukan distribusi pola kedatangan dan waktu pelayanan menggunakan olah data IBM SPSS Statistics 20.

Hipotesis untuk pola kedatangan dalam penelitian ini adalah sebagai berikut:

H0 : Pola kedatangan berdistribusi Poisson

H1 : Pola kedatangan tidak berdistribusi Poisson

Hipotesis untuk waktu pelayanan dalam penelitian ini adalah sebagai berikut:

H0 : Waktu pelayanan berdistribusi eksponensial H1 : Waktu pelayanan tidak berdistribusi eksponensial

2. Menghitung ukuran keefektifan antria pada pelayanan administrasi menggunakan WInQSB, yaitu:

a. Faktor pemanfaatan

b. Nilai harapan banyaknya mahasiswa/umum dalam sistem antrian.

c. Nilai harapan banyaknya mahasiswa atau umum dalam antrian

Metodologi penelitian dapat digambarkan dalam gambar 1 alur metodologi penelitian sebagai berikut: 


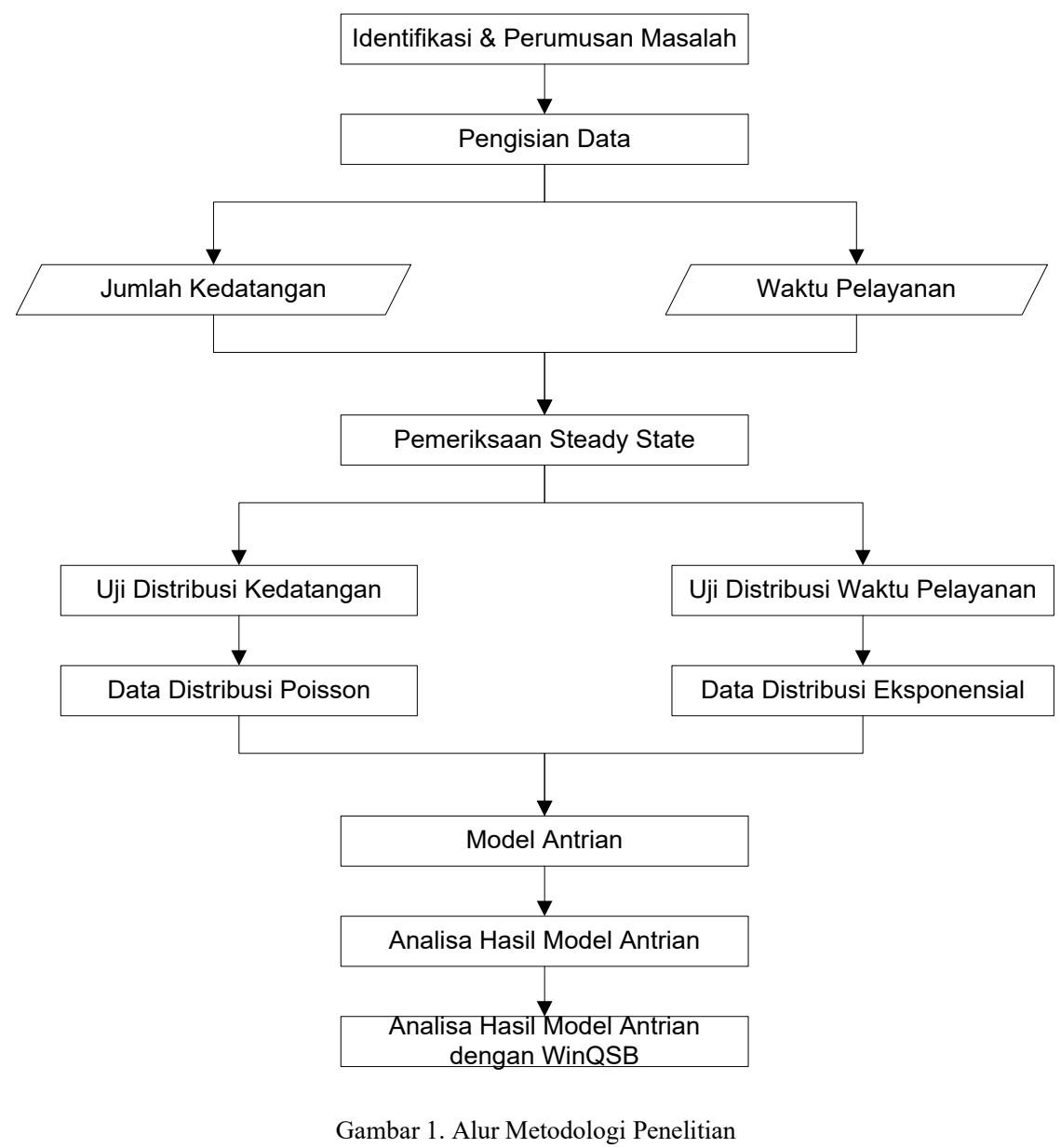

\section{ANALISIS DAN PERANCANGAN}

\section{Analisis Model Antrian}

Perhatikan alur atau proses berikut yang menunjukkan proses poisson dari tiga asumsi pada kondisi antrian dimana kedatangan (kejadian) terjadi selama interval waktu. Perhatikan proses antrian suatu waktu sebagai berikut (Subekti \& Binatari, 2017):

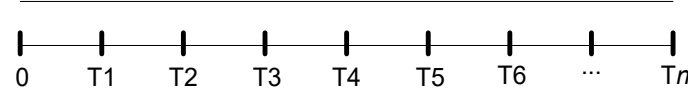

\section{Misalkan:}

$T_{n}=$ waktu yang ditunjukkan saat (pengunjung) ke$n$ datang

$X_{n}=$ waktu antar kedatangan (pengunjung) ke- $n$ dan (pengunjung) yang datang ke- $n-1$

$X_{n}=T_{n}-T_{n-1}$

Asumsi 2 dapat dinyatakan sebagai berikut: $P\left(X_{n}>t\right)>0$ untuk setiap $t>0$

Asumsi 3
Untuk h kecil satu kejadian mungkin terjadi, maka asumsi 2 berlaku untuk setiap Xn bilangan real, sehingga $P\left(X_{n}>t\right)>0$ untuk setiap $t>0$

kemudian dari asumsi 1, diketahui bahwa $P(X>t+s \mid X>s)=P(X>t)$

sehingga diperoleh bahwa

$$
\begin{array}{r}
P(X>t)=P(X>t+s \mid X>s) \\
P(X>t)=\frac{P(X>t+s \cap X>s)}{P(X>s)} \\
P(X>t)=\frac{P(X>t+s)}{P(X>s)}
\end{array}
$$

Jadi $P(X>t+s)=P(X>t) P(X>s)$

Berikut akan di tunjukkan bahwa interval waktu antara dua kejadian berturut-turut adalah eksponensial.

Andaikan notasi $P(X>t)=G(t) \quad$ sehingga terbentuk:

$G(t+s)=G(t) G(s)$

akan dicari fungsi $G$ yang memenuhi persamaan (1), untuk sembarang $t, s$ bilangan real.

Misalkan $G(1)=c$, maka

$G(n)=G(1+1+1+\cdots$

$G(n)=G(1) G(1) G(1) \cdots$ 
$G(n)=c^{n}$

kemudian

$c=G(1)$

$c=G\left(\frac{1}{n}+\frac{1}{n}+\cdots \quad 1\right)$

$c=G\left(\frac{1}{n}\right) G\left(\frac{1}{n}\right) \cdots(1)$

$c=\left(G\left(\frac{1}{n}\right)\right)^{n}$

sehingga berakibat,

$c^{\frac{1}{n}}=G\left(\frac{1}{n}\right)$

dari (2) dan (3), untuk $t$ bilangan rasional berlaku

$c^{\frac{m}{n}}=G\left(\frac{m}{n}\right)$

secara umum, untuk $t$ sembarang bilangan real nonnegatif berlaku

$G(t)=c^{t}$ untuk setiap $t \geq 0$

Jadi

$(X>t)=G(t)=c^{t}=e^{\ln c^{t}}=e^{-\lambda t} \quad$ untuk setiap $t \geq 0$

dengan $\lambda=-\ln c$

sehingga

$1-P(X \leq t)=P(X>t)=e^{-\lambda t}$

atau $P(X \leq t)=1-e^{-\lambda t}$ untuk setiap $t \geq 0$

diberikan fungsi $f(t)$ adalah fungsi densitas peluang atas interval waktu $t$ antara kedatangan yang berurutan, $t \geq 0$

maka

$\int_{0}^{t} f(s) d s=P(X \leq t)$

sehingga

$f(t)=\frac{d}{d t}\left(1-e^{-\lambda t}\right)$

$f(t)=\lambda e^{-\lambda t}$

telah tertunjukkan bahwa $f(t)=\lambda e^{-\lambda t}$ untuk setiap $t \geq 0$ eksponensial.

\section{B. Implementasi Model Antrian}

Hipotesis menentukan langkah-langkah pengujian menggunakan tes satu sampel Kolmogoro-Smirnov, sebagai berikut:

H0 : Data sampel hasil observasi dapat dianggap berasal dari populasi yang berdistribusi Poisson

H1 : Data sampel hasil observasi tidak dapat dianggap berasal dari populasi yang berdistribusi Poisson

Pengambilan data dilakukan dengan mencatat waktu datang dan waktu selesai pelayanan yang memasuki pelayanan administrasi.

Tabel 1. Hasil Uji Poisson

One-Sample Kolmogorov-Smirnov Test

\begin{tabular}{|ll|r|}
\hline & & VAR00003 \\
\hline $\mathrm{N}$ & & 28 \\
Poisson Parameter ${ }^{\mathrm{a}, \mathrm{b}}$ & Mean & 1.71 \\
& Absolute & .075 \\
Most Extreme Differences & Positive & .031 \\
& Negative & -.075 \\
Kolmogorov-Smirnov Z & & .396 \\
Asymp. Sig. (2-tailed) & & .998 \\
\hline
\end{tabular}

a. Test distribution is Poisson.

b. Calculated from data.

Sumber: Hasil Olah SPSS

Hasil uji poisson (Tabel 1) nilai Asymp. Sig (p-value) 0.998 lebih dari alpha 0.05, sehingga H0 diterima dan data terdistribusi poisson. Kesimpulan dari hasil uji poisson diperoleh bahwa data kedatangan berdistribusi poisson dengan rata-rata 1.71.

Bagian pelayanan administrasi di kampus AMIK BSI Bandung menggunakan satu unit komputer dan satu petugas administrasi yang bertugas untuk memberikan pelayanan kepada mahasiswa dan umum. Model antrian yang digunakan pada bagian pelayanan menggunakan model $\mathrm{M} / \mathrm{M} / 1$, sedangkan waktu antar kedatangan di asumsikan terdistribusi eksponensial dengan parameter $(\lambda)$ rata-rata laju kedatangan, waktu pelayanan terdistribusi eksponensial dengan parameter $(\mu)$ rata-rata waktu pelayanan. Banyaknya komputer sebagai server sebanyak satu PC. Komputer tersebut memiliki kapasitas sistem tidak terbatas, dan untuk disiplin layanan antrian menggunakan pertama datang pertama dilayani (First Come First Served).

Ukuran keefektifan sistem antrian diperoleh dari faktor pemanfaatan, nilai harapan banyaknya pelanggan dalam sistem antrian, dan nilai harapan banyaknya pelanggan dalam antrian. Berikut adalah hasil ukuran keefektifan menggunakan WinQSB (Tabel 2). 
Hasil perhitungan WinQSB (Gambar 2) untuk shift pagi/siang.

Banyaknya Server (komputer PC) $M=1$,
Service Rate (per Server per hour) $\lambda=12$, dengan asumsi 60 menit melayani 12 orang Customer arrival rate (per hour) $\mu=1$

Tabel 2. Hasil Perhitungan WinQSB Waktu 07.30-08.30 WIB

\begin{tabular}{|c|c|c|}
\hline 02-01-2018 & Performance Measure & Result \\
\hline 1 & System: M/M/1 & From Formula \\
\hline 2 & Customer arival rate (lambda) per hour = & 1.0000 \\
\hline 3 & Service rate per server (mu) per hour = & 12.0000 \\
\hline 4 & Overall system effective arrival rate per hour = & 1.0000 \\
\hline 5 & Overall system effective service rate per hour = & 1.0000 \\
\hline 6 & Overall system utilization $=$ & $8.3333 \%$ \\
\hline 7 & Average number of customers in the system $(\mathrm{L})=$ & 0.0909 \\
\hline 8 & Average number of customers in the queue $(\mathrm{Lq})=$ & 0.0076 \\
\hline 9 & Average number of customers in the queue for a busy system (Lb) = & 0.0909 \\
\hline 10 & Average time customer spends in the system $\left[W^{\prime}\right]=$ & 0.0909 hours \\
\hline 11 & Average time customer spends in the queue $\left[W^{\prime} q\right]=$ & 0.0076 hours \\
\hline 12 & Average time customer spends in the queue for a busy system $(W / b)=$ & 0.0909 hours \\
\hline 13 & The probability that all servers are idle $\left(\mathrm{P}_{0}\right)=$ & $91.6667 \%$ \\
\hline 14 & The probability an ariving customer waits $(\mathrm{Pw}$ or $\mathrm{Pb})=$ & $8.3333 \%$ \\
\hline 15 & Average number of customers being balked per hour = & 0 \\
\hline 16 & Total cost of busy server per hour = & $\$ 0$ \\
\hline 17 & Total cost of idle server per hour $=$ & $\$ 0$ \\
\hline 18 & Total cost of customer waiting per hour = & $\$ 0$ \\
\hline 19 & Total cost of customer being served per hour = & $\$ 0$ \\
\hline 20 & Total cost of customer being balked per hour = & $\$ 0$ \\
\hline 21 & Total queue space cost per hour = & $\$ 0$ \\
\hline 22 & Total system cost per hour = & $\$ 0$ \\
\hline
\end{tabular}

Sumber: Hasil Olah Penulis Menggunakan WinQSB

Ukuran keefektifan sistem antrian pada waktu 07.3008.30 WIB (Tabel 3), yaitu:

- $p=8.3333 \%$, artinya petugas pelayanan administrasi akan sibuk melayani mahasiswa/umum selama $8.33 \%$ waktunya. Sedangkan $91.67 \%$ dari waktunya (idle time) tidak ada pelayanan (istirahat).

- $\quad L s=0.0909$, artinya petugas pelayanan dapat mengharapkan 0.09 orang ( $\approx 1$ orang) yang berada dalam sistem.
- $L q=0.0076$, artinya mahasiswa/umum yang menunggu untuk dilayani dalam sistem sebanyak 0.0076 orang ( $\approx 0$ orang).

- $W s=0.0909$ jam, menunjukkan bahwa rata-rata mahasiswa/umum menunggu dalam sistem selama 0.0909 jam.

- $W q=0.0076$ jam, menunjukkan bahwa waktu rata-rata mahasiswa/umum menunggu dalam sistem selama 0.0076 jam. 
Tabel 3. Hasil Ukuran Keefektifan

\begin{tabular}{|c|c|c|c|c|c|c|c|c|c|c|}
\hline Sift & Waktu & Rabu & Kamis & arrival rate & service rate & $\mathrm{p} \mathrm{( \% )}$ & Ls & Lq & Ws (jam) & Wq (jam) \\
\hline \multirow{5}{*}{ Pagi/Siang } & $07.30-08.30$ & 1 & 1 & 1 & 12 & 8.3333 & 0.0909 & 0.0076 & 0.0909 & 0.0076 \\
\cline { 2 - 11 } & $08.30-09.30$ & 1 & 1 & 1 & 12 & 8.3333 & 0.0909 & 0.0076 & 0.0909 & 0.0076 \\
\cline { 2 - 11 } & $09.30-10.30$ & 2 & 2 & 2 & 12 & 16.6667 & 0.2 & 0.0333 & 0.1 & 0.0167 \\
\cline { 2 - 11 } & $10.30-11.30$ & 3 & 3 & 3 & 12 & 25 & 0.3333 & 0.0833 & 0.1111 & 0.0278 \\
\cline { 2 - 11 } & $11.30-12.30$ & 2 & 2 & 2 & 12 & 16.6667 & 0.2 & 0.0333 & 0.1 & 0.0167 \\
\cline { 2 - 11 } & $12.30-13.30$ & 3 & 3 & 3 & 12 & 25 & 0.3333 & 0.0833 & 0.1111 & 0.0278 \\
\cline { 2 - 11 } & $13.30-14.30$ & 1 & 1 & 1 & 12 & 8.3333 & 0.0909 & 0.0076 & 0.0909 & 0.0076 \\
\hline \multirow{5}{*}{ Sore/Malam } & $14.30-15.30$ & 2 & 0 & 1 & 12 & 8.3333 & 0.0909 & 0.0076 & 0.0909 & 0.0076 \\
\cline { 2 - 11 } & $15.30-16.30$ & 4 & 0 & 2 & 12 & 16.6667 & 0.2 & 0.0333 & 0.1 & 0.0167 \\
\cline { 2 - 11 } & $16.30-17.30$ & 3 & 1 & 2 & 12 & 16.6667 & 0.2 & 0.0333 & 0.1 & 0.0167 \\
\cline { 2 - 11 } & $17.30-18.30$ & 4 & 0 & 2 & 12 & 16.6667 & 0.2 & 0.0333 & 0.1 & 0.0167 \\
\cline { 2 - 11 } & $18.30-19.30$ & 1 & 3 & 2 & 12 & 16.6667 & 0.2 & 0.0333 & 0.1 & 0.0167 \\
\cline { 2 - 11 } & $19.30-20.30$ & 3 & 1 & 2 & 12 & 16.6667 & 0.2 & 0.0333 & 0.1 & 0.0167 \\
\cline { 2 - 10 } & $20.30-21.30$ & 0 & 0 & 0 & 12 & 0 & 0 & 0 & 0 & 0 \\
\hline
\end{tabular}

Sumber: Hasil Olah Penulis Menggunakan WinQSB

Pelayanan administrasi dengan model antrian single channel single phase hasil perhitungan (1-p) didapatkan lebih dari $83 \%$ dari waktu (idle time) tidak ada pelayanan (istirahat). Tidak ada antrian yang signifikan pada proses pelayanan di bagian administrasi, sehingga petugas pelayanan masih cukup dengan 1 orang dan 1 PC komputer, dan bahkan lebih banyak waktu yang tidak digunakan untuk pelayanan.

\section{KESIMPULAN DAN SARAN}

\section{Kesimpulan}

Penelitian yang telah dilakukan memberikan kesimpulan bahwa sistem antrian pada pelayanan administrasi kampus AMIK BSI Bandung mengikuti alur atau pola kedatangan yang berdistribusi poisson. Sedangkan untuk waktu pelayanan tidak berdistribusi eksponensial. Proses antrian pada pelayanan administrasi kampus menggunakan model single channel single phase. Ukuran keefektifan menggunakan WinQSB menunjukkan bahwa pelayanan administrasi sebesar $8,33 \%$ untuk ratarata kedatangan $1, \quad 16.67 \%$ untuk rata-rata kedatangan 2, dan 25\% untuk rata-rata kedatangan 3, sedangkan asumsi rata-rata pelayanan adalah 12 . Tidak perlu penambahan petugas pelayanan dengan idle time lebih besar dari $83 \%$.

\section{Saran}

Model antrian yang dapat digunakan untuk penelitian selanjutnya dapat menggunakan multichannel multi-phase.

\section{DAFTAR PUSTAKA}

Faisal, F. (2005). Pendekatan Teori Antrian : Kasus Nasabah Bank pada Pukul 08.00-11.00 WIB di Bank BNI 46 Cabang Bengkulu. Jurnal Gradien, Vol.1 No.2, 90-97.
Gross, D., \& Harris, C. (1998). Fundamentals Of Queueing Theory, Third Editian. Canada: John Wiley.

Ismiyanti, A., \& Siringoringo, H. (2004). Analisis Antrian Loket Karcis Taman Margasatwa Ragunan. Majalah Ekonomi dan Komputer, No.3 Tahun XII, 107-113.

Kakiay, T. J. (2004). Dasar Teori Antrian untuk Kehidupan Nyata. Yogyakarta: Andi.

Nurfitria, D., Nureni, \& Utami, I. (2016). Analisis Antrian Dengan Model Single Channel Single Phase Service Pada Stasiun Pengisian Bahan Bakar Umum (SPBU) I Gusti Ngyrahrai Palu. Jurnal Ilmiah Matematika dan Terapan, Vo. 12 No.2, 125-138.

Nurhayati, R., \& Kartono, R. (2014). Analisis Proses Antrian Multiple Channel Single Phase Di Loket Administrasi dan Rawat Jalan RSUP Dr. Kariadi Semarang. Unnes Journal of Mathematics, Vol 3 No 1, ISSN 2252-6943, 1-6.

Prihati, Y. (2012). Simulasi Dan Permodelan Sistem Antrian Pelanggan di Loket Pembayaran Rekening XYZ Semarang. Majalah Ilmiah Informatika, Vol 3, No 3, ISSN: 1411-6413, $1-20$.

Rahayu, U. S., Wasono, R., \& Utami, T. W. (2017). Analisis Sistem Antrian Model Multi Phase-Multi Channel Pada Sentra Pelayanan Kios 3 In 1 BBPLK Semarang. Seminar Nasional Pendidikan, Sains dan Teknologi, ISBN 978-602-61599-6-0 (pp. 323-330). Semarang: Universiats Muhammadiyah Semaraang.

Sari, N. S. (2014). Analisis Proses Antrian Multiple Channel Single Phase Di Loket Administrasi dan Rawat Jalan RSUP Dr. Kariadi Semarang. Unnes Journal of Mathematics, Vol 3 No 1, ISSN 2252-6943, 1-6. 
Septiani, A. S., Wigati, P. A., \& Fatmasari, E. Y. (2017). Gambaran Sistem Antrian Pasien Dalam Optimasi Pelayanan Di Loket Pendaftaran Instalasi Rawat Jalan Rumah Sakit Umum Pusat Fatmawati. JKM Jurnal Kesehatan Masyarakat (e-Journal), Volume 5, Nomor 4, Oktober 2017, 1-14.

Siregar, F. M. (2015). Analisis Sistem Antrian Pada Bengkel PT. Global Jaya Perkasa Pekanbaru. Jom FEKON, Vol. 2 No. 2 Oktober 2015, 1-13.

Subekti, R., \& Binatari, N. (2017). Staff Site Universitas Negeri Yogyakarta. Retrieved Maret 28, 2019, from Modul Praktikum Teori Antrian: http://staffnew.uny.ac.id/upload/198410192 008122005/pendidikan/MODUL+PRAKTI KUM+TEORI+ANTRIAN++ FIX+terakhir.pdf.

Taha, H. A. (1996). Riset Operasi. Jilid 2. Binarupa Aksara, Jakarta.

Widjaja, W., \& Deswindi, L. (2010). Sistem Antrian Di Layanan Administrasi Mahasiswa (LAM) Dengan Aplikasi Software Simulasi. JIEMS Journal of Industrial Engineering \& Management Systems, Vol. 3, No 1, February 2010, 21-28. 